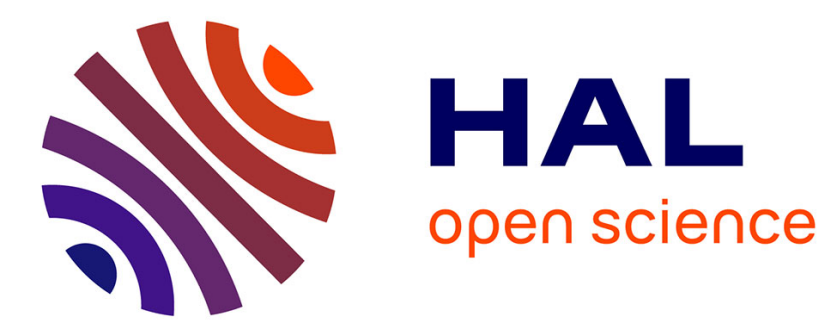

\title{
TRANSFER FUNCTION APPROACH FOR ARTIFICIAL TRACER TEST INTERPRETATION IN KARSTIC SYSTEMS
}

David Labat, A. Mangin

\section{- To cite this version:}

David Labat, A. Mangin. TRANSFER FUNCTION APPROACH FOR ARTIFICIAL TRACER TEST INTERPRETATION IN KARSTIC SYSTEMS. Journal of Hydrology, 2015, 529 (3), pp.866871. 10.1016/j.jhydrol.2015.09.011 . hal-03239237

\section{HAL Id: hal-03239237 \\ https://hal.science/hal-03239237}

Submitted on 27 May 2021

HAL is a multi-disciplinary open access archive for the deposit and dissemination of scientific research documents, whether they are published or not. The documents may come from teaching and research institutions in France or abroad, or from public or private research centers.
L'archive ouverte pluridisciplinaire HAL, est destinée au dépôt et à la diffusion de documents scientifiques de niveau recherche, publiés ou non, émanant des établissements d'enseignement et de recherche français ou étrangers, des laboratoires publics ou privés. 
1 TRANSFER FUNCTION APPROACH FOR ARTIFICIAL TRACER TEST

2 INTERPRETATION IN KARSTIC SYSTEMS

3 Labat D. ${ }^{1}$, Mangin A. ${ }^{2}$

$4 \quad 1$ - Géosciences Environnement Toulouse - Université de Toulouse

$5 \quad 2$ - Station d'Ecologie Expérimentale de Moulis - CNRS

6

7 Revised form for Journal of Hydrology

8

9

10

11 Corresponding author :

12 David LABAT

13 Géosciences Environnement Toulouse - GET

14 14, Avenue Edouard Belin 31400 TOULOUSE FRANCE

15 田 (+33) 5.61.33.26.12

16 Fax: (+33) 5.61.33.25.60

17 E-mail: labat@get.obs-mip.fr 


\section{Abstract}

20 A karstic formation consists in a three-dimensional hydrological system which involves

21 horizontal and vertical, diphasic or saturated water transfers characterised by a large range 22 of velocity. These subsurface flow processes correspond to various water pathways through 23 fractured, fissured, and underground streams or conduits leading to a nonlinear global 24 behaviour of the system.

25 An efficient way of investigating of a karstic system behaviour consists in the injection of artificial tracer tests at loss points and in careful analysis of the recovery tracer fluxes at one or several outlets of the systems. These injections are also an efficient way of providing hypotheses on characteristic time of contaminant transfer in these type of aquifers. Here, we propose a Laplace-transform transfer function of the Residence Time Distribution function that allows to discriminate between a quick-flow advection-dominated component and a slow-flow advection-dispersion/ dominated component in the artificial tracer transfer in the system. We apply this transfer function on five high resolution sampling rate artificial tracer tests operated on the Baget system in the Pyrenees (France) in order to illustrate the advantages and limitations of this approach. We provide then an interpretation of the relationship between tracer test recovery shape and karstic system organisation between inlet and outlet site.

Keywords: artificial tracer tests, karstic system, transfer function, 


\section{Karstic systems as original hydrogeological formations}

Karstic systems are calcareous formations (carbonate rocks) characterised by a fissured and cavernous geomorphology, with significant heterogeneities in water velocities present at different observation scales. Mainly under the action of acidified water infiltration, limestone is submitted to a dissolution process corresponding to a three-phase reaction involving water, gas, and calcite. This process called "karstification" generates a subterranean network of natural cavities and drifts, which become underground reservoirs and rivers, and a typical superficial landscape with dolines and lapiez. Therefore, the subterranean part of the karst is composed of two main parts.

The unsaturated permeable infiltration zone is composed of vertical fissures and natural sink holes that allows rapid and intense recharge and of a finer fissure system that allows diffusive diphasic (air/water) discharge. The saturated (flooded) karst constitutes the main storage of water of the karstic aquifer. This zone is characterized by the presence of two main water storage zones: a highly organized and hierarchized drainage network and the fractured/fissured media around the drainage network. Both zones contribute to the water storage in karstic systems but their strong heterogeneities in term of transmissivity lead to complex hydraulic relationships that explain for a large part the nonlinearity of the karst response. Then, the main peculiarity of karstic aquifers, compared to classical porous media, seems to be the dissociation in the saturated zone of transmissive and capacitive functions. The complexity of the karst systems lead to a number of rainfall-runoff approaches (Charlier et al., 2015, Duran et al., 2015, Hartmann et al., 2013, Jourde et al., 2013, Kong-A-Siou et al., 2014) that could include non linear models coupled to non-stationary analyses tools (Labat et al., 2000, 2001, 2002). We focus here on another systemic approach not based on rainfall impulsions as system entrance but based on artificial tracer injections. The tracer should have some properties such as the non absorbance in the system.

\section{Residence Time Distribution estimation and interpretation}


$77 \quad M=\int_{t=0}^{t=\infty} c(t) Q(t) d t$

78 Where $Q(t)$ is the spring flow function of time $\left(\mathrm{m}^{3} / \mathrm{s}\right)$ and $\mathrm{c}(\mathrm{t})$ is the concentration function of

$$
E(t)=\frac{c(t) Q(t)}{\int_{t=0}^{t=\infty} c(t) Q(t) d t} \text { where } \int_{t=0}^{t=\infty} E(t) d t=1
$$

$$
\theta=\int_{t=0}^{t=\infty} t E(t) d t
$$

Dye tracer experiment constitute one the most effective way to quantify flow and mass transfer in karst aquifers and then infer some hypotheses on the structure of a karstic system. These tests consist in a rapid injection of a fluorescent dye at a supposed recharge 
91 Then, the examination of the tracer breakthrough curve at one of several outlets of the system is supposed to give relevant information about the degree of karstification and connexion of the drainage network system and the presence of internal water reserves in the capacitive areas or not (Massei et al, 2006, Geyer et al., 2007, Goldsheider, 2008). However, one should keep in mind as stated by Maloszewski et al. (2002) that "artificial tracers are usually injected into sinkholes and they usually supply information only on preferential flow paths".

A primary interpretation of the experimental RTD is based on the Advection Dispersion equation that lead to a Log-Gaussian form but when dealing more specifically with karst systems, this approach usually failed reproducing the tail observed on tracer injections in hydrogeological systems. Currently two models are commonly used by the community: QTRACER2 (Field and Pinsky, 2000, Field, 2002) and CXTFIT (Toride et al. 1995, Field and Pinsky, 2000). The first model proposes an analytical solution of the classical advectiondispersion equation and is mainly dedicated to conduit flows. Therefore, it does not allow in general to reproduce the long tail of tracer concentration function of time that we can observe in karst tracer tests for example. The CXFIT program is based on a two region non equilibrium transport model. However, these models suffer of two main limits: it does not lead to a unique interpretation of the karst system and it is based on global parameters such as velocity, dispersivity that should be constant in the karstic system. This point is really crucial. On these models, for example, the dimensionless Peclet number is a crucial parameter. This parameter is defined as a characteristic length of the flow multiplied by the mean velocity and divided by the diffusivity. It also correspond to the product of the Reynolds number by the Schmidt number. But is it reasonable to provide a Peclet number for a flow process in a karst system on several kilometers distance? All these parameters will be characterized by a large 115 interval of variations and for example, it would be very difficult to provide a mean Reynolds 116 number for such flow process. We then propose to follow a new way of tracer test 117 interpretation methods. 


\section{A new transfer function approach}

119 We propose a new paradigm in tracer breakthrough interpretation in karst system based on chemical engineers expertise in control process experience (see Wolf, D., Resnick, W., 121 1963, Levenspiel, 1975, Niemi, 1977, Villermaux, 1982, Nauman E.B., Buffham BA, 1983, Walas, 1991 for example) and first applied to porous media by Sardin et al. (1991). Chemical reactors are a succession of ideally mixed or not reservoirs connected by a network of tubes.

124 In industrial process, the definition and the optimisation of the residence time in each step of the process is crucial. In a similar way, we could consider that in a karst system the tracer (and then mass transfer) follows water movement on a set of different reservoirs such as fracture or fissure networks, annex systems, underground rivers or pipes. However, two main limitations remain:

- The stationarity of the flows,

- The determination of the system and the uniqueness of the solution.

131 For example, Becker and Bellin (2013) proposed a transfer function approach of the MobileImmobile model. Following Dreiss (1982), Mangin (1984) and Labat et al. (2000) among others, we think that a transfer function approach similar to the rainfall/runoff transformation could be applied to the issue of artificial tracer tests interpretation in karstic system. This transfer function should give semi-quantitative information about the relative importance in the tracer test response of a quick-flow component and a slow-flow transfer. The quantification of these two pathways is very important for example in the dissemination of a given contaminant since the predominance of rapid flow implies in general a very tiny attenuation of the pollutant concentration (if there is no adsorption in the system) whereas

140 the predominance of the slow-flow implies in general a dispersion of the pollutant and then a

141 diminution of the peak of pollutant concentration at the outlet of the system. Therefore how

142 can we discriminate the two main components in the RDT function? 
143 In a similar way as in surface hydrology, a classical form of the transfer function could be

144 based on a successive cascade of tanks. However, this model fails here to simulate both the 145 presence of a peak and of a long tail since this model implies either the presence of a peak 146 of high amplitude but with no tail (small number of tanks) or the presence of a peak of small 147 amplitude conjugated to a longer tail (large number of tanks).

148 The model of Becker and Bellin (2013), proposed a cascade of similar transfer functions 149 derived from the mobile-immobile model. The results of simulation leads to set of parameters 150 that are still difficult to interpret in term of physical processes even though if the number of 151 reservoirs could be related to the Peclet number of the system and then to the "complexity" 152 of the flow in the mobile part of the model. Moreover this model does not provide the ability to 153 discriminate between quick and slow components but between a mobile and an immobile 154 part of the fluid transfer. The quick component correspond roughly to flow processes in the 155 drainage network and the highly transmissive fracture network whereas the slow component 156 roughly corresponds to the delayed response in relationship with flow process in less 157 transmissive fractured or fissured zone.

158 We choose to propose a model based on the coexistence of a rapid component and a slow 159 component. We also choose to restrict the number of parameters for each component but to 160 allow the presence of a cascade of similar components that lead to the presence of the 161 exponents $\mathrm{N}_{\mathrm{A}}$ and $\mathrm{N}_{\mathrm{D}}$.

162 Finally, by analogy with experimental models developed in Marsili-Libelli (1997), we propose 163 to use 7 parameters transfer function in the Laplace domain that appear as a convenient 164 compromise between the existence of two components and a limited number of parameters :

$$
H(p)=\alpha\left[\frac{1}{\left(1+A_{1} p\right)\left(1+A_{2} p\right)}\right]^{N_{A}}+(1-\alpha)\left[\frac{1}{\left(1+D_{1} p\right)\left(1+D_{2} p\right)^{2}}\right]^{N_{D}}
$$




$$
\text { Nash }=100\left(1-\frac{\sum\left(y_{\text {mod }}(i)-y_{m e s}(i)\right)^{2}}{\sum\left(y_{\text {mes }}(i)-\overline{y_{\text {mes }}}(i)\right)^{2}}\right)
$$

189 Where $y_{\text {mod }}(i)$ is the discretised time series simulated by the model and $y_{\text {mes }}(i)$ is the discretised experimental time series measured on the field. The optimisation procedure

- $\quad \alpha$ is a coefficient of partition between rapid and slow component and is comprised between 0 and 1 ,

- $A_{1}$ and $A_{2}$ are the two parameters that control the advective component of the transfer function,

- $D_{1}$ and $D_{2}$ are the two parameters that control the slow component of the transfer function,

- $\mathrm{N}_{\mathrm{a}}$ and $\mathrm{N}_{\mathrm{d}}$ are the two exponents respectively of the advective and the slower part of the transfer function.

The first component based on a second-order transfer function correspond to a transport by rapid process whereas we choose to increase the order of the second transfer function in order to reproduce a slower component. We also choose not to propose a large number of parameters $A_{i}$ and $D_{i}$ but to propose that the systems can be connected in series which lead to a multiplication in Laplace domain leading to the $\mathrm{N}_{\mathrm{a}}$ and $\mathrm{N}_{\mathrm{d}}$ exponents. At this point, other choices could be made such as a parallel form of the components of the transfer function but it will lead to a rapid increase of the number of parameters.

The inverse Laplace transform cannot be operated analytically and then we choose to use the algorithm described by de Hoog et al. (1982) and implemented in MATLAB by Hollenbeck (1998). The next step consists in the optimisation procedure that allows the determination of the 7 parameters of the model. The optimisation minimisation criteria between the experimental and the simulated RTD is based on a classical Nash-Sutcliffe (Nash and Sutcliffe, 1970) coefficient:

$$
\text { consists on the application of a genetic algorithm. Genetic algorithm is a searching procedure }
$$


192 based on the mechanics of natural selection and natural genetics. Genetic algorithm has 193 known to be efficient and robust (Wang, 1991) and are based on an artificial survival of the 194 fittest with genetic operators abstracted from nature. In this work a genetic algorithm developed by Dorsey and Mayer (1995) is introduced and applied to the calibration of the parameters of inverse Laplace transform of the $\mathrm{H}(\mathrm{p})$ function. This approach has been applied to five tracer tests operated on a Pyrenean karst.

\section{Results and discussion}

We propose here to apply these functions to several tracer tests experiments over the Baget karstic watershed, part of the SNO Karst consortium. This basin located in the Pyrénées Mountains (Ariège, France) is characterised by a median altitude about $940 \mathrm{~m}$ and an area around $13 \mathrm{~km}^{2}$. The specific runoff is $36 \mathrm{l} / \mathrm{s} / \mathrm{km}^{2}$ with a mean daily runoff about $0.45 \mathrm{~m} / \mathrm{s}$ (Labat et al., 2000). The injections and recovery site are located on the downstream part of the aquifer as depicted in Figure 1. In this zone, the system is characterised by the presence of loss and of temporary and permanent resurgences on a spatially restrained area of about $2 \mathrm{Km}^{2}$.

Five tracer tests based on fluoresceine injection were conducted during periods with norainfall influence in order to avoid any strong variability of the spring flow during the tracer test recovering. On the five tracer tests, the flush of the injected tracer was very rapid (less than one minute) and the tracer directly gets into the loss directly connected to river sinks and drains. By this way, we avoid non-instantaneous but mass-decaying injection at the inlet of the system, due for example to an insufficient flush of the injected tracer and/or to density effects (if the density of the injected solution is higher than that of the groundwater), which may delay the flow of the injected tracer solution into the system. Effectively, the "instantaneous" injection assumption, on which most currently used analytical solutions are based, may be not valid in real field tracer experiments.

The five tracer test characteristics (date, delay, spring flow variations, weight of tracers, and delay of recovery) are shown in Table 1. For each tracer, the spring flow and the 
concentration function of time were measured with a high resolution sampling rate of 8 up to 15 minutes on the most critical part of the recovery. Then, the tracer recovery is sampled on

221 a long time interval but at a lower sampling rate in order to provide a valuable survey of the tail of the RTD function. For the five tests, the tracer recovery rate was superior to $95 \%$. The figures 2 to 6 depict the superposition of the experimental and simulated RTD function but also the representation for each tracer test of the advective and the diffusive slower part of the RTD function. For each simulations, the Nash coefficient was superior to $90 \%$.

A comparison between the recovery simulations of the tracer tests 1, 2 and 3 (or 5) allows to identify in the system different levels of karstification. The tracer test 1 indicates the presence of a drain that allows a rapid advective component in the system response. This advective component corresponds roughly to the maximum at $\mathrm{t}=4 \mathrm{~h}$ highlighted in the global RTD. However, this advective component only corresponds to around $30 \%$ of the integral of the simulated RTD. That indicates that the slow part constitutes the main way of transfer in the aquifer between the injection and the recovery station. The tracer tests 2 and 3 indicates the concomitance between the advective and the slow components with a maximum around $1 \mathrm{~h}$ before the beginning of the recovery and a shift of about 15 minutes. That indicates that the advective part is not predominant in the global RTD and indicates the presence of a less developed drainage system in this area but the presence of a fractured media around this drainage system. The slow component of tracer tests 2 and 3 respectively corresponds to $20 \%$ and $45 \%$ of the integral of the simulated RTD. Therefore, we may think that the fractured media plays a more important role in the water transfer in the inlet-outlet system corresponding to the tracer test 3.

Then, the recovery of tracer tests 3 and 5 allows to identify for a given inlet-outlet system (namely an injection at the P2 loss and a recovery at the Las Hountas spring) possible discrepancies between low (tracer test 5) and medium (tracer test 3) water levels. When the water levels increase, the advective component of tracer tests 3 and 5 respectively corresponds to $55 \%$ and $90 \%$ of the integral of the simulated RTD. On one hand, during low 
246 water periods, the advective component is predominant since all the water flows by the drain 247 and the hydraulic connexion with fractured media is very tiny. On the other hand, during the 248 medium flow periods, the advective and slow components are concomitant since the 249 hydraulic connexion between drainage system and fractured media is characterized by higher piezometric levels in the fractured media.

251 Finally, tracer tests 3 and 4 allows to identify differences in the system organisation since for 252 a given injection point, we examine the tracer test recovery at two different outlets 253 corresponding to two-ways water path is possible in the system. Here, an injection at the P2 254 loss is recovered both at the Las Hountas and Moulo de Jaur outlet. The advective 255 component of tracer tests 3 and 4 respectively corresponds to $55 \%$ and $90 \%$ of the integral of the simulated RTD. Moreover, the maximum of the slow component is delayed in the tracer test 4 compared to tracer test 3 . That indicates that the hydraulic connexion between P2 loss and Moulo de Jaur is characterised by a well organised drainage system whereas the hydraulic connexion between PS loss and Las Hountas is characterised by a drainage system connected to fractured media located in the vicinity of its outlet.

\section{Conclusion}

262 We propose here a new paradigm in the artificial tracer tests interpretation in karstic 263 systems. Following Sardin et al (1991) and Becker and Bellin (2013), we think that a transfer 264 function approach of the RTD function is a very promising way of research. We propose here 265 a transfer function that allows the identification of an advective and a slow part in the water/contaminant transfer and we try to relate the shape of these two components to the degree of karstification of a well-known karstic system Le Baget. That allows to precise the spatial organisation of this system. The following step consists now in the determination of

269 plausible correspondence between the parameters of the transfer functions and physical 270 parameters. Therefore, we strongly encourage karstic community to apply this approach to 271 other systems and to propose if necessary alternative transfer functions but keeping in mind 272 the parsimonious principle. 


\section{Acknowledgment}

This work benefits from INSU/CNRS CRITEX Program RBV-SOERE. The Baget watershed is part of the French national observatory SO KARST (www.sokarst.org). We also thank the three anonymous reviewers for improvements of the initial version.

\section{References}

- Becker M., Bellin A., 2013. A reservoir model of tracer transport for karstic flow systems. Hydrogeology Journal 21, 1011-1019.

- Charlier JB, Ladouche B., Maréchal JC, 2015.Identifying the impact of climate and anthropic pressures on karst aquifers using wavelet analysis. Journal of Hydrology $523,610-623$

- De Hoog F.R., Knight J.H., Stokes A.N., 1982. An improved method for numerical inversion of Laplace transforms. SIAM J Scientific and Statistical Computation, 3, 357-366.

- Dorsey, RE, Mayer W.J., 1995. Genetic algorithms for estimation problems with multiple optima, nondifferentiability, and other irregular features. Journal of Business \& Economic Statistics, 13(1), 53-66.

- Dreiss,S.J., 1982. Linear kernels for karst aquifers. Water Resources Research 18, 865-876.

- Duran L., Fournier M., Massei N., Dupont J.P., 2015. Assessing the Nonlinearity of Karst Response Function under Variable Boundary Conditions, Groundwater in press.

- Field M.S., 2002. The QTRACER program for tracer-breakthrough curve analysis for karst and fractured-rock aquifers, US Environmental Protection Agency.

- Field M.S., Pinsky P.F., 2000. A two-region non equilibrium model for solute transport in solution duits in karstic aquifers. Journal of Contaminant Hydrology 44(3-4) 329351.

- Geyer T., Birk S., Licha T., Liedl R., Sauter M., 2007. Multitracer test approach to characterize reactive transport in karst aquifers. Ground Water 45(1), 36-45.

- Goldsheider N., 2008. A new quantitative interpretation of the long-tail and plateaulike breakthrough curves from tracer tests in the artesian karst aquifer of Stuttgart, Germany. Hydrogeology, 16, 1311-1317.

- Hartmann A., Weiler M., Wagener T., Lange J., Kralik M., Humer F., Mizyed N., Rimmer A., Barberá J.A., Andreo B., Butscher C., Huggenberger P., 2013. Processbased karst modelling to relate hydrodynamic and hydrochemical characteristics to system properties. Hydrology and Earth System Sciences 17(8), 3305-3321

- Hollenbeck K.J., 1998. INVLAP.M : a Matlab function for numerical inversion of Laplace transforms by de Hoog algorithm.

- Jourde H., Lafare A., Mazzilli N., Belaud G., Neppel L., Dörfliger N., Cernesson F., 2013. Flash flood mitigation as a positive consequence of anthropogenic forcing on the groundwater resource in a karst catchment, Environmental Earth Sciences doi:10.1007/s12665-013-2678-3

- Kong-A-Siou L., Fleury P., Johannet A., Estupina VB, Pistre S., Dörfliger N., 2014. Performance and complementarity of two systemic models (reservoir and neural 
networks) used to simulate spring discharge and piezometry for a karst aquifer. Journal of Hydrology 519, 3178-3192.

- Labat D., Ababou R., Mangin A., 2000. Rainfall-runoff relations for karstic springs Part II: Continuous wavelet and discrete orthogonal multiresolution analyses. Journal of Hydrology, 238, pp. 149-178.

- Labat D., Ababou R., Mangin A., 2001. Introduction of wavelet analyses to rainfall/runoffs relationships for a karstic basin: the case of Licq-Atherey karstic system (France). Ground Water, 39, 4, pp. 605-615.

- Labat D., Ababou R., Mangin A., 2002. Analyse multirésolution croisée de pluies et débits de sources karstiques. Comptes Rendus de l'Académie des Sciences de Paris, Géosciences 334, pp. 551-556.

- Levenspiel, O., 1975. Chemical reaction engeering, 478 pp. John Wiley New York.

- Maloszewski, P., Stichler, W., Zuber, A., \& Rank, D. 2002. Identifying the flow systems in a karstic-fissured-porous aquifer, the Schneealpe, Austria, by modelling of environmental $18 \mathrm{O}$ and $3 \mathrm{H}$ isotopes. Journal of Hydrology, 256, 48-59.

- Mangin, A., 1984. Pour une meilleure connaissance des systemes hydrologiques à partir des analyses correlatoire et spectrale. Journal of Hydrology, 67(1-4): 25-43

- Marsili-Libelli S., 1997. Simple model of a transport/diffusion system. IEE ProcControl Theory, 144,5, 459-465.

- Massei ., Wang H.Q., Field M.S., Dupont J.P., Bakalowicz M., Rodet J., 2006. Interpreting tracer breakthrough tailing in conduit dominated karstic aquifer, Hydrogeoglogy Journal 14, 849-858.

- Nash, J. E., and J. V. Sutcliffe (1970), River flow forecasting through conceptual models. Part I - A discussion of principles, J. Hydrology., 10, $282-290$.

- Nauman E.B., Buffham BA, 1983. Mixing in continuous flow systems, Wiley, New York.

- Niemi, A., 1977. Residence time distributions of variable flow processes. International Journal of Applied Radiation and Isotopes, 28,855-860

- Sardin M., Schweich D., Leu F.J., van Genuchten. 1991. Modeling the nonequilibrium transport of linearly interacting solutes in porous media: a review. Water Resource Research, 27(9) 2287-2307.

- Toride N., Leij F.J, Van Genuchten M.T., 1995. A comprehensive set of analytical solutions for nonequilibrium solute transport with first order decay and zero production. Water Resource Research 29(7), 2167-2182.

- Villermaux, J., Génie de la reaction Chimique : conception et fonctionnement des réacteurs, 401 pp, Lavoisier Tec-Doc, Paris 1982.

- Walas, S.M., 1991. Modelling with differential equations in chemical engineering, Butterworth-Heinemann, Boston.

- Wang, Q. J., 1991. The genetic algorithm and its application to calibrating conceptual rainfall-runoff models, Water Resour.Res, Vol 27, No 9, 2467-2471

- Wolf, D., Resnick, W., 1963. Residence time distribution in real systems. I and EC Fundamentals, 2(4) 287-293. 


\section{TABLE 1:}

Description of the five artificial tracer tests operated on the Baget karstic system (Pyrenees, France) used in this study.

\begin{tabular}{|c|c|c|c|c|c|c|}
\hline NAME & DATE & INJECTION & RECOVERING & $\begin{array}{l}\text { WEIGHT } \\
\text { (G) }\end{array}$ & $\begin{array}{c}\text { MEAN } \\
\text { SPRING } \\
\text { FLOW }\left(\mathbf{M}^{3} / \mathbf{S}\right)\end{array}$ & $\begin{array}{l}\text { SAMPLING } \\
\text { RATE (MIN) }\end{array}$ \\
\hline TRACER TEST 1 & $12 / 10 / 1977$ & La Peyrère & Las Hountas & 160 & 0.07 & 15 \\
\hline TRACER TEST 2 & $15 / 12 / 1977$ & Moulo de Jaur & Las Hountas & 50 & 0.275 & 15 \\
\hline TRACER TEST 3 & 07/03/1978 & P2 Loss & Las Hountas & 750 & $0.650 \pm 0.05$ & $8-15$ \\
\hline TRACER TEST 4 & 07/03/1978 & P2 Loss & Moulo de Jaur & 750 & $0.355 \pm 0.01$ & $8-15$ \\
\hline TRACER TEST 5 & 03/05/1979 & P2 Loss & Las Hountas & 700 & $0.340 \pm 0.01$ & $8-15$ \\
\hline
\end{tabular}




\section{FIGURE 1:}

Top: Localization of the Baget karstic system and description of the watershed. The inlet and outlet tracer injection/recovery are located in the upstream part of the basin (black rectangle).

Bottom: Zoom on the injection/recovery sites used in the five tracer tests of the study and localization of the gauge station

\section{FIGURE 2:}

Comparison between experimental (EXP) and simulated (MOD) RTD function and visualization of the advective (blue line) and slow (dark dashed line) component based on the equation 4 for the tracer test 1.

\section{FIGURE 3:}

Idem for tracer test 2.

\section{FIGURE 4:}

Idem for tracer test 3.

\section{FIGURE 5:}

Idem for tracer test 4 .

\section{FIGURE 6:}

Idem for tracer test 5 . 